\title{
The Use of Neupogen (Filgrastim) or Neulasta (Pegfilgrastim) during Pregnancy When Chemotherapy Is Indicated for Maternal Cancer Treatment
}

\author{
Elyce Cardonick, Farhana Irfan, Natalie Torres \\ Cooper University Hospital, Cooper Medical School at Rowan, Camden, USA. \\ Email: torresns@umdnj.edu
}

Received February 3 $3^{\text {rd }}, 2012$; revised March $3^{\text {rd }}$, 2012; accepted March $19^{\text {th }}, 2012$

\begin{abstract}
Introduction: Little is known about the effects stem cell mobilizers (GCSF) such as neulasta (pegfilgrastim) or neupogen (filgrastim) during pregnancy, and these are often withheld from women undergoing chemotherapy during pregnancy. Materials and Methods: Women receiving chemotherapy during pregnancy were identified from the Cancer and Pregnancy Registry maintained at Cooper University Hospital, Cooper Medical School at Rowan. 176 pregnant women who received chemotherapy were identified. Their oncologists were asked if neupogen or neulasta were "prescribed when necessary;" "were not necessary;" or "were held due to pregnancy.” Birth outcomes, white blood count at birth and pediatric health were compared between the group receiving Neupogen/Neulasta (exposed) and a control group (unexposed), i.e. chemotherapy without neupogen/neulasta). Independent $T$ Test or Pearson Chi Square were implemented for statistical comparisons. Results: The mean gestational age at delivery was not significantly different between the exposed ( $35.4 \pm 2.8$ weeks) and unexposed groups $(35.9 \pm 2.8$ weeks) $\mathrm{p}=0.465$. The mean birth weights were not significantly different, $2433 \pm 567 \mathrm{~g}$ (exposed) compared with $2673 \pm 723 \mathrm{~g}$ in unexposed group, $\mathrm{p}=0.07$. Nor was there a difference in congenital malformations: $11.7 \%$ versus $4.8 \% . \mathrm{p}=0.22$. The incidence of non-iatrogenic preterm births or complications was not statistically different between groups. Mean WBC count in the exposed group was $13.04 \pm 5.0$ cells per cubic millimeter of blood and in the unexposed group was $14.6 \pm 7.2, p=0.24$. Conclusion: We did not find a statistically significant difference in gestational age at birth, congenital anomalies, or birth weight, incidence of long term medical issues, mean WBC or neutropenia at birth between the newborns exposed to Neupogen/ Neulasta with chemotherapy and newborns exposed to chemotherapy alone.
\end{abstract}

Keywords: Neurogen; Neulasta; Chemotherapy; Pregnancy

\section{Introduction}

Women diagnosed with cancer during pregnancy may receive chemotherapy [1-4]. Granulocyte-Stimulating Colony Factor, or G-CSF, also known as stem cell mobilizers such as neulasta (pegfilgrastim) or neupogen (filgrastim) are routinely administered to non-pregnant patients undergoing chemotherapy to bolster immunity and reduce the risk of infection. Little is known about the effects of such agents during pregnancy. Filgrastim and neupogen are recombinant human colony stimulating factors which regulate the proliferation and differentiation of hematopoietic stem cells and selectively support the clonal growth of progenitors of neutrophils. Filgrastim/peg-filgrastim have been used to prime neutrophils to increase expression of chemotactic factors and bactericidal phagocytic activity. Often, neuopgen/neulasta are withheld with chemotherapy in pregnancy due to lack of studies of safety. Neutropenia could expose the pregnant patient to superimposed infections such as cytomegalovirus which can be harmful to the developing fetus. If pregnant women do develop neutropenia, can Neupogen or Neulasta be prescribed? In this paper we report its use during pregnancy with chemotherapy in a cohort study.

\section{Materials and Methods}

Women receiving chemotherapy during pregnancy were identified from the Cancer and Pregnancy Registry maintained at Cooper University Hospital, Cooper Medical School at Rowan. The Cancer and Pregnancy Registry was established in 1997 to monitor the diagnosis, clinical course, treatment and pregnancy and survival outcomes of women diagnosed with cancer during pregnancy. Establishment of the Cancer and Pregnancy Registry has been approved by the Institutional Review 
Board and enrollment is voluntary. Two hundred fifty five women have enrolled from North America, Europe, Africa and Australia. Details of chemotherapy administration during pregnancy including the decision to use or withhold stem cell mobilizers was collected. The obstetrician provided details of any pregnancy or delivery related complications and the pediatrician caring for the neonate was asked to provide results of the umbilical cord and/or neonatal complete blood count with differential collected at birth. Oncologists were asked if neupogen or neulasta were "prescribed when necessary;" "were not necessary;" or "were held due to pregnancy." Yearly neonatal follow-up is requested from each child's pediatrician. Patients not receiving neupogen/neulasta will be referred to as the "unexposed group." Outcomes were compared between the exposed and unexposed groups. Independent $\mathrm{T}$ Test or Pearson Chi Square was implemented for statistical comparisons.

\section{Results}

Two hundred fifty five women with cancer diagnosed during pregnancy were identified from the Registry. Of these, 176 received chemotherapy before delivery. The majority were treated for breast cancer. Other cancer types include Hodgkin's Lymphoma, Non Hodgkin's Lymphoma, Acute Leukemia, Cervical, Central Nervous System, Colorectal, Lung, Ovarian, Pancreatic cancer and Sarcoma. The mean maternal age at diagnosis was $34.2 \pm$ (4.8) years. Thirty four women were given neupogen/neulasta before delivery. One hundred forty two women receiving chemotherapy during pregnancy did not receive neupogen/neulasta. Of the 142, 98 oncologists gave no reason, 40 reported the patient "did not require neupogen or neulasta" and 4 oncologists withheld stem cell mobilizers "due to pregnancy concerns."

The mean gestational age at diagnosis was $14.07 \pm 7.7$ weeks. The mean gestational age at first chemotherapy treatment was $20.1 \pm 6.1$ weeks. See Table 1 for details of cancer diagnoses, use of chemotherapy and G-CSF.

The mean gestational age at delivery for the cohort of neonates was $35.8 \pm 2.8$ weeks. This was not significantly different between the exposed (35.4 \pm 2.8 weeks) and unexposed group $(35.9 \pm 2.8$ weeks $) \mathrm{p}=0.465$. The mean birth weights were not significantly different, 2433 $\pm 567 \mathrm{~g}$ (exposed) compared with $2673 \pm 723 \mathrm{~g}$ in unexposed group, $p=0.07$. See Table 2 . The incidence of

Table 1. Maternal information.

\begin{tabular}{ccc}
\hline Cancer type & Total \# Chemotherapy & \#Neupogen/Neulasta \\
Breast & 122 & 22 \\
Hodgkin's Lymphoma & 25 & 4 \\
Non-Hodgkin's Lymphoma & 10 & 6 \\
Ovarian & 7 & 0 \\
Miscellaneous (Pancreas, CNS, Sarcoma, Rectal, Lung, Cervical, Colon) & 9 & 2 \\
Acute Leukemia & 3 & Total \\
& Total & 34 \\
\hline
\end{tabular}

Table 2. Delivery details.

\begin{tabular}{cccc}
\hline & Neupogen/Neulasta-No & Neupogen/Neulasta-Yes & P-value \\
\hline Gestational Age at Delivery Mean (SD) weeks & $35.9(2.8)$ & $35.4(2.8)$ & 0.465 \\
Birth Weight Mean (SD) grams & $2673(723)$ & $2433(567)$ & 0.07 \\
Incidence of spontaneous preterm labor/PPROM/Abruptio N (\%) & $9 / 34(26 \%)$ & $21 / 143(14 \%)$ & 0.10 \\
Complications at birth & $9 / 34(26 \%)$ & $21 / 143(14 \%)$ & 0.10 \\
Congenital malformations N (\%) & $7(4.8 \%)$ & $4(11.7 \%)$ & 0.22 \\
White Blood Count: Mean (SD) & $14.6(7.23)$ & $13.04(5.0)$ & 0.24 \\
Neutropenia & $2(1.3 \%)$ & $1(2.9 \%)$ & 0.48 \\
\hline
\end{tabular}


preterm deliveries secondary to spontaneous premature rupture of membranes, spontaneous preterm labor or medically indicated conditions such as previa/abrupio/ deteriorating maternal or fetal status (all noniatrogenic preterm deliveries) was compared between groups. This was not significantly different between groups: 21/143 (14\%) in the unexposed group and 9/34 (26\%) in the exposed group, $\mathrm{p}=0.09$. Complications during pregnancy, delivery or in the newborn period were compared between groups. Complications for the newborn at birth: exposed (9/34) vs. unexposed (21/142) were not significantly different, $\mathrm{p}=0.10$ Complete blood count with differential was requested in all patients receiving chemotherapy during pregnancy but was only sent in 31 cases. The blood collection time ranged from time of birth up to two days postnatally. Of the 34 exposed to neupogen or neulasta, 20 had a CBC and differential performed.

Mean WBC count in the exposed group was $13.04 \pm$ 5.0 cells per cubic millimeter of blood and in the unexposed group mean WBC count was $14.6 \pm 7.2$ cells per cubic millimeter of blood. This was not statistically different, $p=0.24$. See Table 2 . Two children in the unexposed group and one child in the exposed group developed neutropenia. The p-value for this comparison is 0.48 (Fisher Exact Test). None of the children in either group were treated for infections at birth or in the newborn period.

There were 4 children born with major congenital malformations in the exposed group, (11.7\%), and 7 children in the non-exposed group, (4.8\%). Using Fisher Exact Test, this was not statistically different, $\mathrm{p}=0.22$. Birth defects are further detailed in Table 3. Of the 11 major birth defects, 6 were apparent at birth. Five were identified later at 6 weeks (pyloric stenosis), 4 and 6 months (plagiocephaly), 13 (epibulbar dermoid cyst) and 22 months of age (hemihypertrophy). The incidence of congenital malformations at birth was 3.4\%. By two years of age, the incidence was $6.2 \%$. One child in the exposed group was found prenatally to have AV Canal defect and Down Syndrome. The sonogram and amniocentesis diagnosing and confirming these findings were performed prior to beginning chemotherapy.

Neonatal follow-up information is requested from pediatricians yearly. Twenty nine of the 34 exposed and 114 of the unexposed group provided follow up to a mean age of $54.0 \pm 37$ months. Information requested includes height, weight, clinical developmental age compared to chronological age (developmental quotient), and any medical conditions or special services such as speech therapy ordered. Comparisons were made between groups for behavioral or speech issues, eczema, and asthma since these were recurring medical issues in each group. See Table 4 . There were no significant differences between groups: behavioral issues: exposed 0/29) vs. unexposed (3/114), $\mathrm{p}=1.00$; Speech $(1 / 29)$ vs. $2 / 114$ $\mathrm{p}=0.50$; eczema: exposed $1 / 29)$ vs. unexposed $(3 / 114)$ $=>\mathrm{p}=0.58$; and asthma: exposed (3/29) vs. unexposed

Table 3. Congenital Anomalies: Both groups exposed to chemotherapy, with or without supporter medication.

\begin{tabular}{|c|c|c|c|}
\hline $\begin{array}{l}\text { Exposed to chemotherapy with } \\
\text { Neupogen/Neulasta }\end{array}$ & $\begin{array}{l}\text { Age at diagnosis of } \\
\text { anomaly }\end{array}$ & $\begin{array}{l}\text { Chemotherapy without } \\
\text { Neupogen/Neulasta }\end{array}$ & $\begin{array}{l}\text { Age at diagnosis of } \\
\text { anomaly }\end{array}$ \\
\hline Syndactyly & Birth & Pyloric stenosis & 6 weeks \\
\hline Spina bifida & Suspected prenatally & Hemihypertrophy & 22 months \\
\hline AV Canal Defect, Down Syndrome & Suspected prenatally & $\begin{array}{l}\text { Gastroschisis, miscarriage } 1 \text { week } \\
\text { after chemotherapy }\end{array}$ & 19 weeks \\
\hline \multirow[t]{4}{*}{ Plagiocephaly } & 6 months & Plagiocephaly & 4 months \\
\hline & & Renal pelvis dilation & Suspected prenatally \\
\hline & & UPJ obstruction requiring pyeloplasty & Suspected prenatally \\
\hline & & Epibulbar dermoid cyst & 13 months \\
\hline
\end{tabular}

Table 4. Medical follow up of newborns.

\begin{tabular}{cccc}
\hline Medical Issue & Exposed to Neupogen/Neulasta & Chemotherapy without NEupogen/NEulasta & P value \\
\hline Behavioral & $0 / 29(0 \%)$ & $3 / 114(2.6 \%)$ & 1.0 \\
Asthma & $3 / 29(10.3 \%)$ & $5 / 114(4.4 \%)$ & 0.18 \\
Eczema & $1 / 29(3.4 \%)$ & $3 / 114(2.6 \%)$ & 0.58 \\
Speech & $1 / 29(3.4 \%)$ & $2 / 114(1.7 \%)$ & 0.50 \\
\hline
\end{tabular}


$(5 / 114)=>p=0.18$.

\section{Discussion}

Information about the use of neupogen/neulasta/GCSF during pregnancy is limited to case reports. When chemotherapy is required during pregnancy, the risk of neutropenia could risk opportunistic infections which could affect the fetus. Calhoun et al. demonstrated that giving recombinant G-CSF to pregnant women may result in the transplacental passage of a measurable quantity of granulocyte colony-stimulating factor that can have a biologic effect on the fetus, especially if administered at least 30 hours before delivery [5]. Several authors reported normal newborn outcomes at birth after late trimester exposure to neupogen/neulasta by [6-11]. Two cases reported normal white blood cell indices for the infants, a third reported WBC $3.1 \times 10^{9} / \mathrm{L}$ with a left shift $[7,8,10]$.

In 2005, Niedermeier reported a woman diagnosed with acute myeloid leukemia at 21weeks treated with cytarabine and idarubicin [12]. Piperacillintazobactam and clindamycin therapy were given for sepsis. Filgrastim $16 \mathrm{mug} / \mathrm{kg}$ was added at 29 weeks to improve stem cell mobilization. At term, she delivered a viable but growth restricted female infant with congenital abnormalities. Complete blood count of the infant was normal. Anomalies included a shallow sacral dimple, short digits and limbs, prominent frontal skull with mild macrognathia and a membranous ventricular septal defect which required surgical repair at 5 months. The underlying maternal leukemia is a known risk factor for intrauterine growth restriction. Both chemotherapy was started and filgrastim added after organogenesis was completed. Detailed sonogram performed prior to beginning chemotherapy was not mentioned aside form a normal left ventricular function of the fetal heart. In the case report by Leitner no gross anomalies were reported after first trimester exposure to Filgrastim during organogenesis, without chemotherapy.

There are case reports with exposures earlier in pregnancy. Ohba treated a pregnant patient with aplastic anemia with G-CSF throughout pregnancy. She delivered a normal infant with growth restriction at term however the pregnancy was complicated by hypertension which can affect birth weight. The infant's WBC was normal [13]. Leitner reported a patient receiving G-CSF preconceptually until 8 weeks gestation. At birth and up until the age of 18 months of age there was no evidence of hematological or immunological alterations [14].

The Severe Chronic Neutropenia International Registry (SCNIR) collected data on 16 pregnancies in 48 women who received Filgrastim (average dose 2.7 ug $/ \mathrm{kg} / \mathrm{d}$ ) for an average of 2 trimesters. Filgastrim exposure did not lead to higher rates of fetal death or congenital anomalies compared to the outcomes of 105 identified pregnancies without filgrastim exposure. Authors found a higher rate of spontaneous miscarriage and newborns requiring prolonged hospitalizations among women who did not receive filgrastim during pregnancy. There is safety data for use during childhood as well. (SCNIR) data shows no adverse effect of filgrastim on childhood growth or development after use as a treatment for severe chronic neutropenia [15]. In post-marketing retrospective reports of pregnancies reported to the drug company, of 9 pregnant women taking filgrastim 4 reported congenital anomalies (renal,cardiac), 4 reported normal pregnancy outcomes, and 1 reported a spontaneous miscarriage. Women with a child born with a congenital anomaly are more likely to report their drug exposure during pregnancy. Similar outcomes have not been found among prospectively collected cases of isolated filgrastrim exposure [15].

In our retrospective analysis of women exposed to chemotherapy, we did not find a statistically significant difference in gestational age at birth, congenital anomalies, or birth weight, mean WBC or neutropenia at birth or incidence of long term medical issues between groups exposed and unexposed to Neupogen (filgrastim) or Neulasta (pegfilgrastim). All newborns undergo physical exam after birth, pediatricians did not report splenomegaly in any newborns. On yearly follow up pediatricians did not report any neonates succumbing to opportunistic infections.

Limitations of this analysis include the small number of women exposed to Neupogen (filgrastim) or Neulasta (pegfilgrastim) during pregnancy. Although more data needs to be collected, if one is considering an iatrogenic preterm delivery close to administration of chemotherapy, one may consider filgrastim/peg-filgastim to protect the preterm infant. A second consideration for use during pregnancy would be to protect the unborn fetus from CMV and other opportunistic infections if pregnant women develop neutropenia during chemotherapy.

\section{REFERENCES}

[1] A. Aviles, J. C. Diaz-Maqueo, A. Talavera, R. Guzman and E. L. Garcia, "Growth and Development of Children of Mothers Treated with Chemotherapy during Pregnancy: Current Status of 43 Children," American Journal of Hematology, Vol. 36, No. 4, 1991, pp. 243-248. doi:10.1002/ajh.2830360404

[2] D. L. Berry, R. L. Theriault, F. A. Holmes, V. M. Parisi, D. J. Booser, S. E. Singletary, et al., "Management of Breast Cancer during Pregnancy Using a Standardized Protocol,” Journal of Clinical Oncology, Vol. 17, No. 3, 1999, pp. 855-861. 
[3] R. C. Doll, Q. S. Ringenberg and J. W. Yarbo, “Antineoplastic Agents and Pregnancy," Seminars in Oncology, Vol. 16, 1989, pp. 337-345.

[4] E. Cardonick and A. Iacobucci, "Use of Chemotherapy during Human Pregnancy,” Lancet Oncology, Vol. 5, 2004, pp. 263-291. doi:10.1016/S1470-2045(04)01466-4

[5] D. A. Calhoun, C. Rosa and R. D. Christensen, "Transplacental Passage of Recombinant Human Granulocyte Colony-Stimulating Factor in Women with an Imminent Preterm Delivery," American Journal of Obstetrics \& Gynecology, Vol. 174, No. 4, 1996, pp. 1306-1311. doi:10.1016/S0002-9378(96)70676-2

[6] R. Fujiwaki, T. Hata, K. Hata, M. Kitao, H. Furuya and Y. Katoh, "Effective Treatment of Drug-Induced Agranulocytosis Using Recombinant Human Granulocyte Colony Stimulating Factor in Pregnancy," Gynecologic and $\mathrm{Ob}$ stetric Investigation, Vol. 40, No. 4, 1995, pp. 276-277. doi:10.1159/000292355

[7] H. A. Arango, C. S. Kalter, S. L. Decesare, J. V. Fiorica, G. H. Lyman and W. N. Spellacy, "Management of Chemotherapy in a Pregnancy Complicated by a Large Neuroblastoma," Obstetrics \& Gynecology, Vol. 84, No. 4, Part 2, 1994, pp. 665-668.

[8] S. J. Kaufmann, K. Sharif, V. Sharma and B. A. McVerry, "Term Delivery in a Woman with Severe Congenital Neutropenia, Treated with Growth Colony Stimulating Factor," Human Reproduction, Vol. 13, No. 2, 1998, pp. 498-499. doi:10.1093/humrep/13.2.498

[9] T. Abe, H. Azuma, A. Watanabe, T. Shigekiyo, S. Endou, R. Pou, R. Fukui, K. Maeda, T. Aono and T. Matsumoto, "A Patient with Cyclic Neutropenia Complicated by Severe Persistent Neutropenia Successfully Delivered a Healthy Baby,” Internal Medicine, Vol. 39, No. 8, 2000, pp. 663-666. doi:10.2169/internalmedicine.39.663

[10] M. R. Sangalli, M. Peek and A. McDonald, "Prophylactic Granulocyte Colony-Stimulating Factor Treatment for Acquired Chronic Severe Neutropenia in Pregnancy," Australian and New Zealand Journal of Obstetrics and Gynaecology, Vol. 41, No. 4, 2001, p. 470.

[11] M. Kikkawa, S. Matsubara, M. Takatoku, T. Kuwata, A. Ohkuchi, A. Izumi, T. Watanabe, M. Suzuki, "Granulocyte-Colony Stimulating Factor for the Treatment of Ritodrine-Induced Neutropenia,” Journal of Obstetrics and Gynaecology Research, Vol. 34, No. 2, 2008, pp. 286-290. doi:10.1111/j.1447-0756.2008.00773.x

[12] D. M. Niedermeier, D. A. Frei-Lahr and P. D. Hall, "Treatment of Acute Myeloid Leukemia during the Second and Third Trimesters of Pregnancy," Pharmacotherapy, Vol. 25, No. 8, 2005, pp. 1134-1140. doi:10.1592/phco.2005.25.8.1134

[13] T. Ohba, T. Yoshimura, M. Araki, J. Miyoshi, Y. Yonemura, K. Matsuura and H. Okamura, "Aplastic Anemia in Pregnancy: Treatment with Cyclosporine and Granulocyte-Colony Stimulating Factor," Acta Obstetricia et Gynecologica Scandinavica, Vol. 78, No. 5, 1999, pp. 458461.

[14] G. Leitner, H. Loidolt, H. T. Greinix, P. Höcker and M. Dettke, “Granulocyte Colony Stimulating Factor-Induced Allogenic Peripheral Stem Cell Donation during Early Pregnancy,” British Journal of Haematology, Vol. 115, No. 1, 2001, pp. 233-234.

[15] T. E. Cottle, C. J. Fier, J. Donadieu and S. E. Kinsey, "Risk and Benefit of Treatment of Severe Chronic Neutropenia with Granulocyte Colony-Stimulating Factor," Seminars in Hematology, Vol. 39, No. 2, 2002, pp. 134140. doi:10.1053/shem.2002.31914 